\title{
Ultrasonic-Assisted Aqueous Two-Phase Extraction and Properties of Water-Soluble Polysaccharides from Malus hupehensis
}

\author{
Pengcheng $\mathrm{Li}^{1,2,+}{ }^{1}$, Hongkun Xue ${ }^{3, \dagger}$, Mi Xiao ${ }^{1}$, Jintian Tang ${ }^{3}$, Hansong $\mathrm{Yu}^{2, *}$, Yanqi $\mathrm{Su}^{1, *}$ and Xu Cai ${ }^{3, *}$ (1) \\ 1 China Pharmaceutical Preparation Section, Huazhong University of Science and Technology Union Jiangbei \\ Hospital/Wuhan Caidian People's Hospital, Wuhan 430100, China; LPC951010@163.com (P.L.); \\ xm15926389307@163.com (M.X.) \\ 2 College of Food Science and Engineering, Jilin Agricultural University, Changchun 130033, China \\ 3 Key Laboratory of Particle \& Radiation Imaging, Ministry of Education, Department of Engineering Physics, \\ Tsinghua University, Beijing 100084, China; xuehk@mail.tsinghua.edu.cn (H.X.); 13769140853@163.com (J.T.) \\ * Correspondence: yuhansong@jlau.edu.cn (H.Y.); suyanqi@sohu.com (Y.S.); \\ caixu@mail.tsinghua.edu.cn (X.C.); Tel.: +86-010-62-796-784 (X.C.) \\ + These authors contributed equally to this work.
}

check for updates

Citation: Li, P.; Xue, H.; Xiao, M.; Tang, J.; Yu, H.; Su, Y.; Cai, X. Ultrasonic-Assisted Aqueous Two-Phase Extraction and Properties of Water-Soluble Polysaccharides from Malus hupehensis. Molecules 2021, 26, 2213. https://doi.org/10.3390/ molecules 26082213

Academic Editors: Marcel Popa and Lesław Juszczak

Received: 15 March 2021

Accepted: 8 April 2021

Published: 12 April 2021

Publisher's Note: MDPI stays neutral with regard to jurisdictional claims in published maps and institutional affiliations.

Copyright: (c) 2021 by the authors. Licensee MDPI, Basel, Switzerland. This article is an open access article distributed under the terms and conditions of the Creative Commons Attribution (CC BY) license (https:/ / creativecommons.org/licenses/by/ $4.0 /)$.
Abstract: Malus hupehensis (M. hupehensis), an edible and medicinal plant with significant antioxidant and hypoglycemic activity, has been applied to new resource foods. However, the structural characterization and biological effects of its polysaccharides (MHP) are less known. The optimum extraction parameters to achieve the highest extraction efficiency $(47.63 \%)$, the yield (1.68\%) and purity of MHP (89.6\%) by ultrasonic-assisted aqueous two-phase system (ATPS) were obtained under the liquid-to-solid ratio of $23 \mathrm{~g} / \mathrm{mL}$, ultrasonic power of $65 \mathrm{~W}$, and ultrasonic time of $33 \mathrm{~min}$. According to the analysis results, MHP was composed of Man, GlcA, Rha, GalA, Glc, Gal, Xyl, Ara, and Fuc, in which Ara and Gal were the main components, and the content of GlcA was the lowest. In in vitro activity analysis, MHP showed a significant antioxidant capacity, and an inhibition activity of $\alpha$-glucosidase and the advanced glycation end products (AGEs) formation in the BSA/Glc reaction model. MHP interacted with $\alpha$-glucosidase and changed the internal microenvironment of the enzyme, and inhibited the AGEs formation, which provides more evidence for the antihyperglycemic mechanism of MHP. The results suggest that ATPS is an efficient and environmentally friendly solvent system, and M. hupehensis has broad application prospects in functional foods, healthcare products, and pharmaceuticals.

Keywords: Malus hupehensis; polysaccharide; ultrasonic assisted aqueous two-phase system; structural characterization

\section{Introduction}

Malus hupehensis (Pamp.) Rehder (M. hupehensis), an edible and medicinal plant, is known as the most important species for ornamental value in the genus Malus, and extensively distributed in southern China [1,2]. As an antipyretic drink with time honored history, a pot of tea by using three pieces of leaves is very popular in Hubei province of China [3,4]. It has a variety of pharmacological activities, including antioxidative, antihyperglycemic, antitumor ability, which are established on the presence of polyphenols and flavonoids [5,6]. Owing to its security and health functions, the extract of $M$. hupehensis has been applied to new resource foods and supplements [7,8]. Due to the significant antioxidant and hypoglycemic effect, $M$. hupehensis is a typical traditional Chinese medicine (TCM) and healthy tea to treat type 2 diabetes in the folk traditions [8,9]. However, there is seldom systematic research about polysaccharides from M. hupehensis (MHP) contributing to the antioxidant and hypoglycemic effects, which prompted us to perform a detailed investigation. 
Polysaccharides, as abundant natural molecules, are widely used for food and pharmaceutical industries. The interesting bioactivities and diverse structures of polysaccharides have been developed in TCM, which makes TCM activate the antioxidant defense system, the immune system, and the endocrine system, etc. [10,11]. For example, antitumor polysaccharides from Ganoderma lucidum, three antioxidant polysaccharides obtained from Agaricus blazei Murrill, antidiabetic polysaccharides from Grifola frondosa Mycelium, four hypoglycemic polysaccharides from corn silk [10-13]. The extraction and application of polysaccharides is the interesting research point of the medicine and biology field. The structural and biological properties of polysaccharides are closely related to their molecular weight, monosaccharide composition, and three-dimensional structures [14].

The effective extraction of bioactive polysaccharides from natural plants is the significant operation. Various conventional extraction techniques, including hot water extraction, ultrasonic assisted extraction, pressurized water extraction and microwave assisted extraction, etc., have been developed. The efficient and rapid preparation of polysaccharides in one-step is a great challenge [15]. The crude polysaccharides extract should be refined by consuming organic solvents and a complex series of operations prior to applications because of coexisting impurities. However, the repeated elution processes of conventional solid sorben are usually time-consuming, laborious, and lead to the serious loss of target compounds caused by the highly irreversible adsorptive property [16]. The aqueous two-phase system (ATPS) is composed of two kinds of immiscibility polymers or one polymer and salts with water, which have been extensively performed on the extraction and purification of polysaccharides, proteins and other biomolecules in a single step [17]. Polysaccharides were enriched in one phase of APTS under the selectivity of van der Waals' forces, hydrophobic effect, electrostatic effect, and interfacial tension. Compared with conventional extraction methods, ATPS is the environmentally friendly and highly efficient extraction solvent system that provides a gentle, biocompatible environment for target compounds, and shows the merits of negligible viscosity, quick phase separation, and the excellent solubility [18]. As previously reported, polysaccharides were obtained from aloe leaves, Ziziphus Jujuba, Solanum nigrum, and Lentinus edodes through ATPS, and these results provided the new possibilities for the rapid extraction and purification of polysaccharides [19-22]. The extraction efficiency, an important evaluation index of ATPS extraction for polysaccharides, was affected by many factors, which needs to be further elucidated.

In this study, the objective of this work was to (1) optimize the extraction conditions for MHP by the response surface methodology (RSM), then establish a rapid and effective extraction method based on ultrasonic-assisted aqueous two-phase system (UAATPS); (2) analyze the preliminary characterizations of MHP according to chemical analysis and modern chromatography; (3) study the potential antioxidant and hypoglycemic activity of MHP for food and pharmaceutical applications.

\section{Results and Discussion}

\subsection{Selection of Ethanol/Salt ATPS}

The phase diagrams and extraction efficiency of different ATPSs are shown in Figure 1. The phase-separation ability of five salts were ranked in the order as follows: $\left(\mathrm{NH}_{4}\right)_{2} \mathrm{SO}_{4}$ $<\mathrm{NaH}_{2} \mathrm{PO}_{4}<\mathrm{K}_{2} \mathrm{HPO}_{4}<\mathrm{Na}_{2} \mathrm{CO}_{3}<\mathrm{Na}_{2} \mathrm{HPO}_{4}$. The order was consistent with the phase forming ability of different salts that are quantitatively described by Gibbs free energy of hydration [23,24]. However, the extraction efficiency of MHP was inversely proportional to the phase-separation ability. $\left(\mathrm{NH}_{4}\right)_{2} \mathrm{SO}_{4}$ was more beneficial as the phase-forming salt based on the higher extraction efficiency. In addition, when the concentration of $\left(\mathrm{NH}_{4}\right)_{2} \mathrm{SO}_{4}$ was located in the range of $18-23 \%(w / w)$, the extraction efficiency of MHP improved with the increase in $(\mathrm{NH} 4)_{2} \mathrm{SO}_{4}$ concentration. 

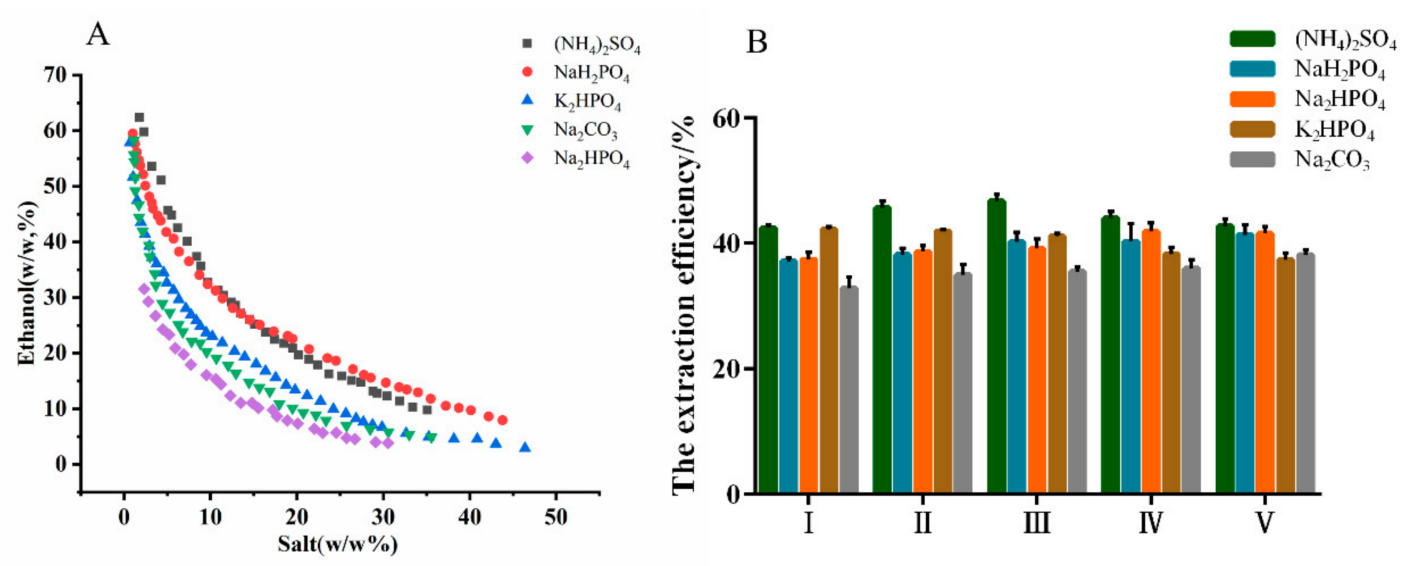

Figure 1. Binodal curves for aqueous two-phase system composed of ethanol/salts at $25^{\circ} \mathrm{C}$, and atmospheric pressure (A), and the effect of the compositions of aqueous two-phase system on the extraction efficiency of polysaccharides from Malus hupehensis (B): mass fraction of ethanol/salt (\%).

A maximum extraction efficiency of $46.70 \%$ was obtained at the $(\mathrm{NH} 4)_{2} \mathrm{SO}_{4}$ concentration of $19.86 \%(w / w)$, which may be attributed to the salt-out effect. Therefore, ethanol/(NH4) ${ }_{2} \mathrm{SO}_{4}$ ATPS was selected as the extraction system for the following studies, and the optimal parameters were as follows: ATPS composition of ethanol concentration at $30.31 \%(w / w)$ and $(\mathrm{NH} 4)_{2} \mathrm{SO}_{4}$ concentration at $19.86 \%(w / w)$.

\subsection{RSM Optimization}

\subsubsection{Single Factor Experiments}

The ultrasonic time (10-50 $\mathrm{min})$ and material-liquid ratio $(1: 10-1: 30 \mathrm{~g} / \mathrm{mL})$ on the extraction efficiency of MHP were studied to optimize the extraction process and determine the influence of ultrasonic power $(40-80 \mathrm{~W})$. The results of single factor experiments showed that the extraction efficiency of MHP was correlated with ultrasonic power, ultrasonic time, and material-liquid ratio. As shown in Figure 2A, at a certain range, the extraction efficiency of MHP could be increased by increasing the ultrasonic power. The increase in ultrasonic power could promote the fragmentation of plant tissue and improve the solubility of MHP. The maximum extraction efficiency of MHP was $43.98 \%$ when the ultrasonic power was $60 \mathrm{~W}$. The extraction efficiency of MHP decreased with the ultrasonic power exceeding $60 \mathrm{~W}$ because the structure of MHP was changed and degraded due to the high ultrasonic power [25]. As shown in Figure 2B, at a certain range, the extraction efficiency of MHP could be increased by increasing the ultrasonic time. The longer the extraction time, the stronger the heat accumulation effect, thus promoting the diffusion rate of MHP. The extraction efficiency of MHP reached a maximum value of $45.31 \%$ at $30 \mathrm{~min}$. The increase in ultrasonic time could destroy the cell tissue and dissolve the MHP solute. When the ultrasonic time was further increased, the extraction efficiency of MHP decreased due to the structural change and degradation of MHP because of the long ultrasonic time and the enhanced thermal accumulation effect [26]. Figure 2C shows that when the material-liquid ratio was 1:10-1:20 $(\mathrm{g} / \mathrm{mL})$, the extraction efficiency of MHP increased significantly with the increase of this ratio $(p<0.05)$, and the maximum extraction efficiency of MHP reached $45.39 \%$ when the ratio was 1:20 $(\mathrm{g} / \mathrm{mL})$. The reason was when the material-liquid ratio was increased, the concentration difference between the internal and external solvents of the plant tissue was larger and the permeability and diffusion force of MHP increased, thus promoting the dissolution of MHP solute. When the material-liquid ratio was further increased, the extraction efficiency of MHP decreased due to the decrease in concentration gradient between the solute and the solvent and the decrease in MHP diffusion force [27]. Meanwhile, the loss of MHP increased and the extraction efficiency of MHP decreased slowly in the process of MHP collection. Therefore, 
three factors and three levels were selected for response surface test: ultrasonic power of $50-70 \mathrm{~W}$, ultrasonic time of $20-40 \mathrm{~min}$, and material-liquid ratio of $1: 15-1: 25 \mathrm{~g} / \mathrm{mL}$.
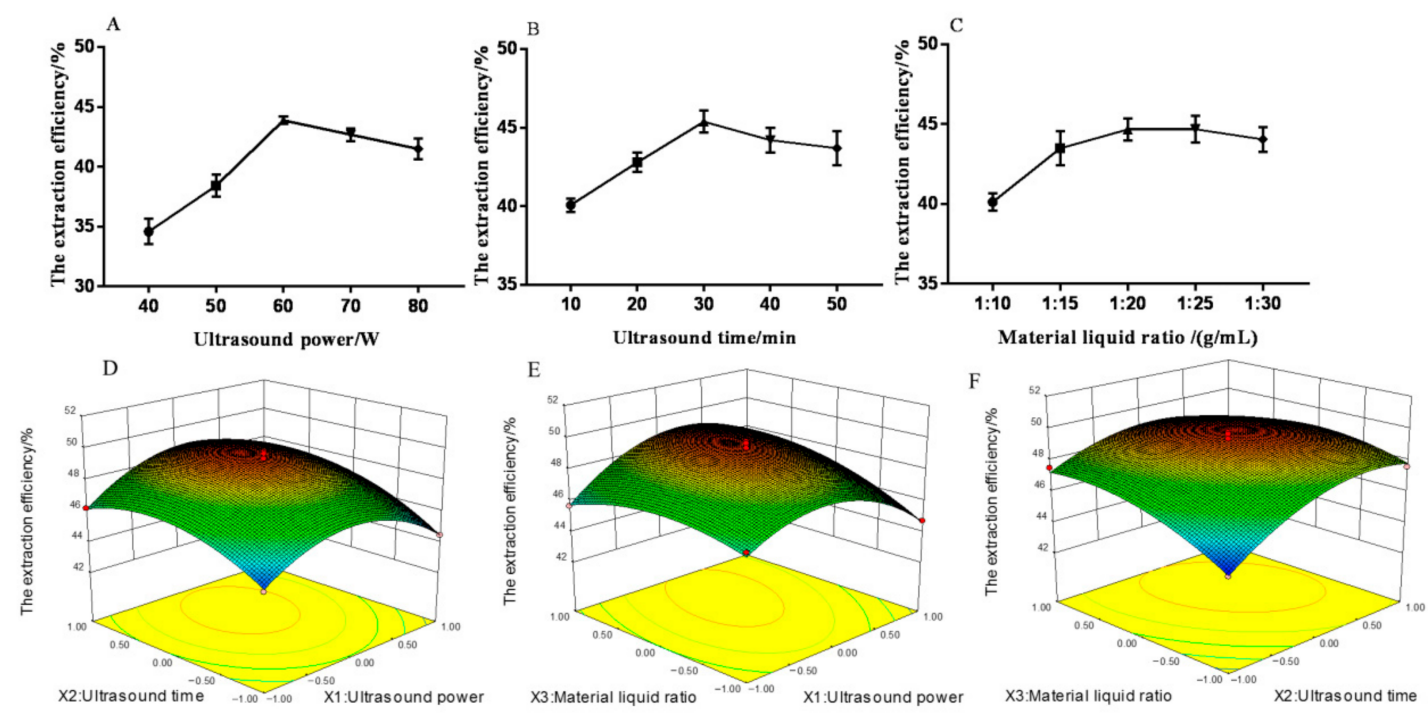

Figure 2. Effect of ultrasonic power (A), ultrasonic time (B), material-liquid ratio (C), ultrasonic power and ultrasonic time (D), ultrasonic power and material-liquid ratio (E), ultrasonic time and material-liquid ratio (F) on the extraction efficiency of polysaccharides from Malus hupehensis.

\subsubsection{Model Establishment and Significance Test}

The optimal process conditions of response surface were optimized in accordance with the results of single factor experiments. The experimental design and results are shown in Table S4. The extraction efficiency of MHP $(E)$ used as the response value, the regression Equation (1) of ultrasonic power $X_{1}$, ultrasonic time $X_{2}$, and material-liquid ratio $X_{3}$ with the extraction efficiency were obtained.

$$
\begin{gathered}
E=49.32+0.11 X_{1}+0.97 X_{2}+0.68 X_{3}+0.34 X_{1} X_{2} \\
+0.89 X_{1} X_{3}-0.67 X_{2} X_{3}-2.23 X_{1}^{2}-1.44 X_{2}^{2}-1.01 X_{3}^{2}
\end{gathered}
$$

Table S4 shows the results of ANOVA. F value could test the significance of each variable on the response value. The larger the $F$ value, the higher the significance of the corresponding variables. The model significance test was $p<0.05$, and the determination coefficient $\left(R^{2}\right)$ was 0.9727 . The model showed a statistical significance, but the lack-of-fit was not significant. Therefore, the response model could be used to analyze and predict the optimal extraction process of MHP.

\subsubsection{Interaction Analysis}

In accordance with the regression equation, a three-dimensional surface graph was established to determine the optimal extraction conditions. The results are shown in Figure 2. The interaction between ultrasonic power and material-liquid ratio as well as ultrasonic time and material-liquid ratio significantly affected the extraction efficiency of MHP $(p<0.05)$. The interaction of other factors had no significant effect on the extraction efficiency of MHP.

The regression equation was further analyzed by Design-Expert software, and the optimal process conditions were obtained as follows: ultrasonic power of $65 \mathrm{~W}$, ultrasonic time of $33 \mathrm{~min}$, material-liquid ratio of $1: 23 \mathrm{~g} / \mathrm{mL}$, and the theoretical extraction efficiency of MHP of $48.78 \%$. Validation test was carried out to verify the reliability of the method, the average value was $47.63 \%$ after the test was repeated three times. The MHP yield was $1.68 \%$, and the purity was $89.6 \%$. The results showed that the model could well 
simulate and predict the content of MHP, thereby proving the feasibility of the REM optimization process.

\subsection{FT-IR Analysis}

The characteristic absorption peaks of MHP are shown in Figure 3A. The O-H stretching vibration at $3400 \mathrm{~cm}^{-1}$ and the $\mathrm{C}-\mathrm{H}$ stretching vibration at $2940 \mathrm{~cm}^{-1}$ were the characteristic absorption peaks of polysaccharide [28]. Absorption peaks at 1730 and $1420 \mathrm{~cm}^{-1}$, which were asymmetric $\mathrm{COO}$ stretching vibration, were also found. The peaks indicated that galacturonic acid may exist in MHP. The symmetrical COO stretching vibration at $1610 \mathrm{~cm}^{-1}$ indicated the existence of ester group in MHP [29]. The stretching vibration of $\mathrm{C}-\mathrm{O}$ with ether bond at $1080 \mathrm{~cm}^{-1}$ belonged to the asymmetric absorption peak of glycosidic bond, and the weak absorption peak at $845 \mathrm{~cm}^{-1}$ indicated a small amount of $\alpha$-glycosidic bond [28].

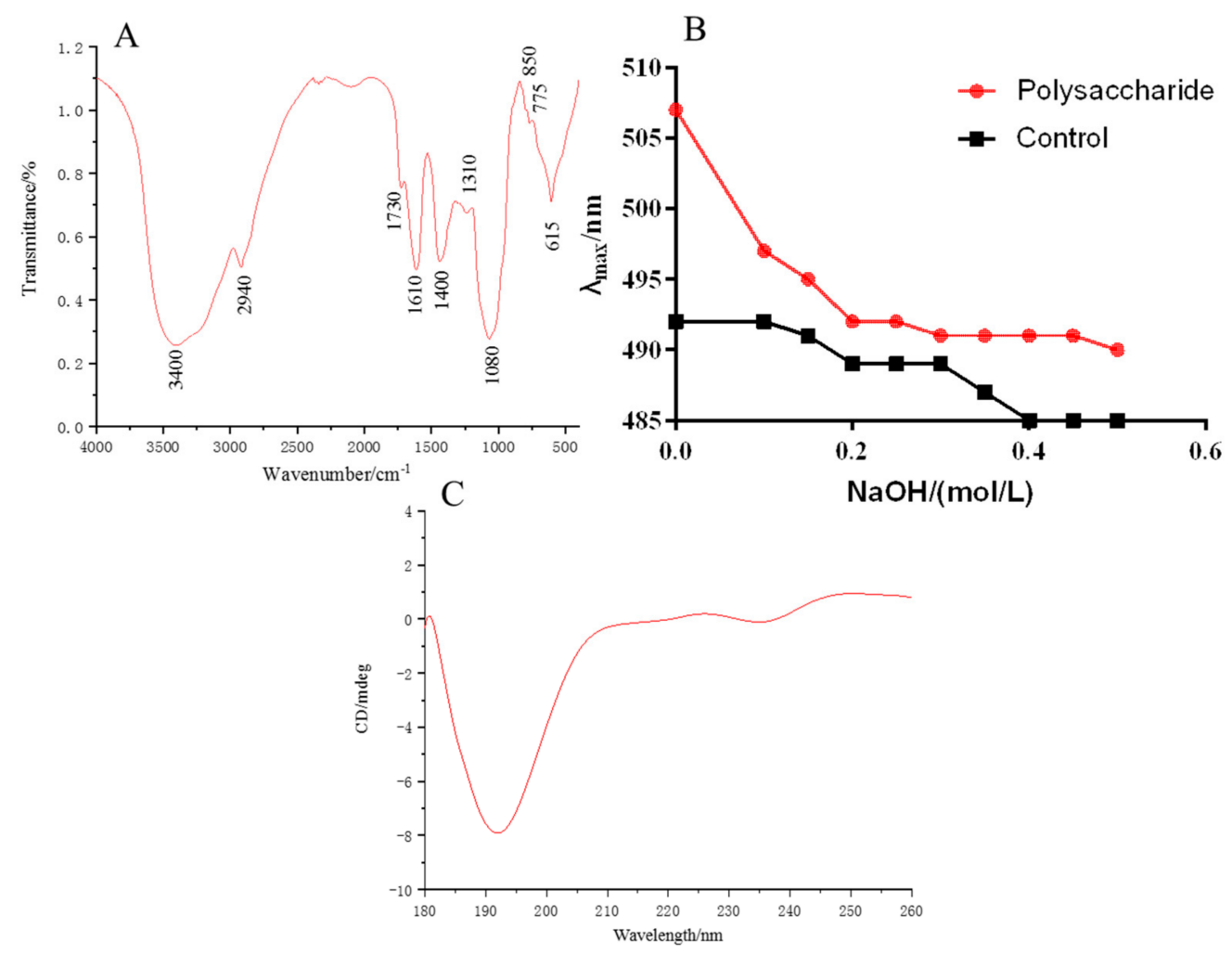

Figure 3. FT-IR spectra of polysaccharides (A), maximum absorption wavelength of polysaccharides-Congo red (B) and CD chromatogram (C).

\subsection{Monosaccharide Composition Analysis}

The chromatogram of PMP derivatization of MHP hydrolysate is shown in Table 1. MHP was composed of Man, GlcA, Rha, GalA, Glc, Gal, Xyl, Ara, and Fuc, with molar ratios of 3.22:1.85:4.25:5.08:6.69:38.46:4.68:30.90:4.87, and the contents of Gal and Ara were the highest at $38.46 \%$ and $30.90 \%$, respectively. The results showed that MHP was mainly composed of Gal and Ara. Some studies have shown that polysaccharides with Ara showed a certain hypoglycemic effect. For example, when starch was eaten with Ara, it could effectively reduce the blood sugar level; when Ara instead of sucrose, it may reduce blood glucose; Ara can inhibit the absorption of sucrose and alleviate high glucose induced oxidative stress $[30,31]$. Therefore, MHP may have a good hypoglycemic effect. 
Table 1. Monosaccharide composition analysis.

\begin{tabular}{ccccccccc}
\hline \multicolumn{10}{c}{ Monosaccharide Composition (\%) } \\
\hline Man & GlcA & Rha & GalA & Glc & Gal & Xyl & Ara & Fuc \\
\hline 3.22 & 1.85 & 4.25 & 5.08 & 6.69 & 38.46 & 4.68 & 30.90 & 4.87 \\
\hline
\end{tabular}

\subsection{Congo Red and Circular Dichroism Analysis}

Congo red could detect whether polysaccharides have a triple helix structure. The polysaccharide with triple helix structure could form a complex with Congo red, and its maximum absorption wavelength increases and red shift occurs. Figure 3B illustrates that when the $\mathrm{NaOH}$ concentration increased, the maximum absorption wavelength of the solution decreased, indicating that the triple helix structure of MHP was destroyed by the higher concentration of $\mathrm{NaOH}$ and could not form a complex with Congo red. Thus, its red shift disappeared. As shown in Figure 3C, an obvious negative button effect existed at $193 \mathrm{~nm}$, indicating that MHP has an asymmetric structure.

\subsection{In Vitro Antioxidant Activity}

The antioxidant activity of MHP was determined by DPPH, ABTS, and hydroxyl and superoxide radical systems, and vitamin $C$ was used as the positive control. ABTS radical scavenging capacity detection method could be used to detect the antioxidant capacity of hydrophilic and lipophilic substance, and it is the most widely used indirect detection method [32]. The results of ABTS radical scavenging activity of MHP are shown in Figure 4A. The ability of ABTS radical scavenging increased with the increase in concentration. When the MHP concentration was $2000 \mu \mathrm{g} / \mathrm{mL}$, the strongest scavenging effect of MHP on ABTS free radical was $57.59 \% \pm 3.67 \%$ and the $\mathrm{IC}_{50}$ value was $467.49 \pm 13.72 \mu \mathrm{g} / \mathrm{mL}$.

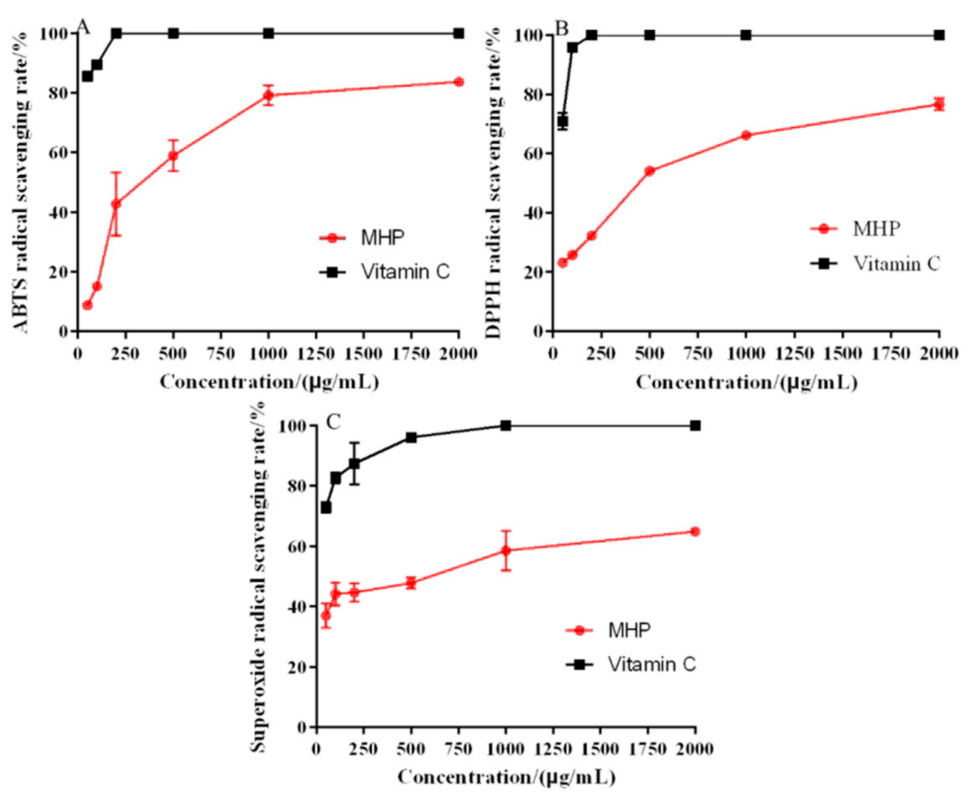

Figure 4. In vitro antioxidant activity: the scavenging rate of ABTS (A), DPPH (B), and superoxide radical $(\mathbf{C})$.

DPPH radical scavenging mechanism was based on DPPH radical as hydrogen ion acceptor; thus, DPPH was converted into a non-free radical (DPPH-H) [33]. Figure 4B shows that the DPPH radical scavenging ability of MHP was related to its concentration. In the range of 50-2000 $\mu \mathrm{g} / \mathrm{mL}$, the scavenging capacity was significantly enhanced, and the maximum scavenging rate was $75.42 \% \pm 1.26 \%$. In general, the lower the $\mathrm{IC}_{50}$ value, the stronger the antioxidant activity. The $\mathrm{IC}_{50}$ value of $\mathrm{DPPH}$ radical scavenging activity 
was $487.57 \pm 8.67 \mu \mathrm{g} / \mathrm{mL}$. The results showed that MHP could be used as a hydrogen donor to combine with DPPH radical to form a more stable substance, thus scavenging DPPH radicals.

Superoxide free radical is a kind of reactive oxygen free radical produced in the human body. It could trigger lipid peroxidation in the body. Therefore, the antioxidant activity of compounds could be evaluated by scavenging superoxide radicals in vitro [34]. As shown in Figure 4C, the superoxide radical scavenging was the strongest at $2000 \mu \mathrm{g} / \mathrm{mL}$, which was $64.87 \% \pm 2.63 \%$, and the $\mathrm{IC}_{50}$ value was $684.53 \pm 8.39 \mu \mathrm{g} / \mathrm{mL}$.

The antioxidant activity of MHP extracted using UAATPS showed a dose-dependent relationship as its antioxidant capacity increased with the increase in MHP concentration. Compared with polysaccharides from wheat bran, dandelion roots and Porphyra haitanensis, MHP has a significant antioxidant activity [33-35]. It is therefore a source of active compounds that might be used as potential antioxidant.

\subsection{In Vitro Antihyperglycemic Activity}

\subsection{1. $\alpha$-Glucosidase Inhibitory Activity}

$\alpha$-glucosidase inhibitors could inhibit enzyme activity and slow down the decomposition of sugars in the human body, thereby delaying the absorption rate of glucose. Therefore, they play an important role in controlling blood glucose and diabetes. As shown in Figure 5A, the inhibitory effect of MHP on $\alpha$-glucosidase showed a concentrationdependent relationship at the concentration of $250-3000 \mu \mathrm{g} / \mathrm{mL}$, and its $\mathrm{IC}_{50}$ value was $994.52 \pm 10.63 \mu \mathrm{g} / \mathrm{mL}$. Although the inhibitory activity of MHP is worse than that of acarbose and wheat bran polysaccharides, as a natural product, it does not produce side effects on the human body $[36,37]$. Thus, it shows a great hypoglycemic potential.

A

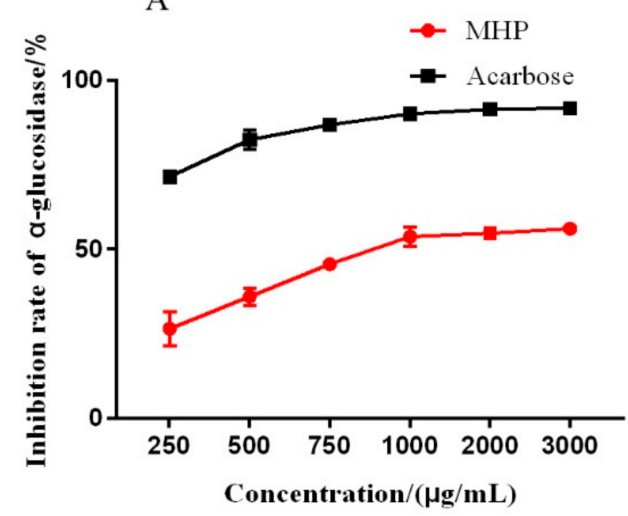

B

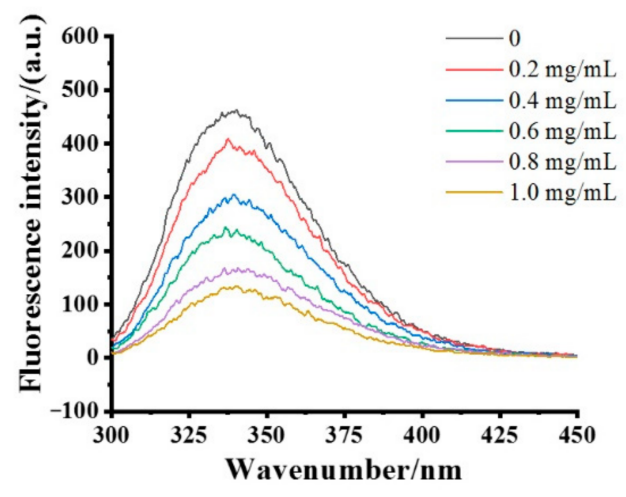

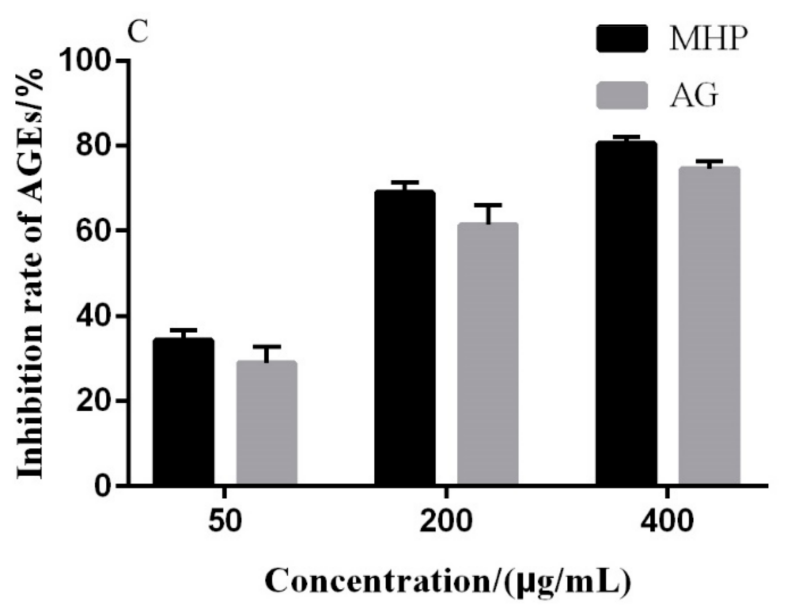

Figure 5. $\alpha$-glucose inhibitory activity (A), the quenching effect of polysaccharides on fluorescence spectra of $\alpha$-glucosidase (B) and effect of polysaccharides on the formation of fluorescent AGEs (C). 
According to the amino acid sequence of $\alpha$-glucosidase from Saccharomyces cerevisiae with NCBI, $\alpha$-glucosidase is composed of 589 amino acid residues and 20 tryptophan (Trp) residues, which could provide intrinsic fluorescence. When a fluorescent substance interacts with other substances, its fluorescence intensity decreases, which is called fluorescence quenching. The fluorescence intensity of $\alpha$-glucosidase gradually weakened with the increase MHP concentration. Results indicated that the fluorescence of $\alpha$-glucosidase was affected by concentration-dependent quenching. Moreover, the absorption peak of $\alpha$-glucosidase (about $331 \mathrm{~nm}$ ) gradually shifted to the right under different MHP concentrations (Figure 5B). The right shift phenomenon implied that the polarity of the microenvironment around Trp residues in $\alpha$-glucosidase changed and became more hydrophilic after the addition of MHP [38]. Many studies showed that the polysaccharide with moderate molecular weight and high water solubility has the biological activity, while that with double helix or triple helix structure has better biological activity than other polysaccharides [14]. In the present study, MHP had a certain triple helix structure. Therefore, the $\alpha$-glucosidase inhibitory activity was related to the change of the microenvironment around Trp residues in $\alpha$-glucosidase that may be caused by the triple helix structure of MHP.

\subsubsection{Inhibition of MHP on AGEs Formation}

Studies have shown that continuous hyperglycemia causes nonenzymatic glycosylation of many proteins and the formation of AGEs, which play an important role in the pathogenesis of chronic complications of diabetes, senility, kidney dysfunction, and cardiovascular disease [39]. In the present study, the capability of antiglycation of MHP was evaluated on the basis of the inhibition rate of fluorescent AGEs. As shown in Figure 5C, the inhibitory effect of AGEs was dependent on the concentration of MHP. At a concentration of $400 \mu \mathrm{g} / \mathrm{mL}$, the inhibition ratio of MHP reached around $80 \%$, and the $\mathrm{IC}_{50}$ value was $143.78 \pm 5.62 \mu \mathrm{g} / \mathrm{mL}$. It was reported that polysaccharides from pumpkin and Coptis chinensis showed the similar antiglycation effect [39,40]. Therefore, MHP can be used to decrease AGEs in human body to help prevent or control diseases like diabetes and senility.

\section{Materials and Methods}

\subsection{Material and Chemicals}

Malus hupehensis (Pamp.) Rehder was purchased from Lishizhen Chinese herbal medicine market (Huanggang, Hubei Province, China). The samples were identified by Professor Bisheng Huang, Department of Pharmacy, Hubei University of Chinese Medicine. Specimens of the samples were deposited in Department of Engineering Physics, Tsinghua University (Voucher Specimen Number, 20201028). The samples were smashed and sieved by an 80 meshes sieve, extracted by petroleum ether for $2 \mathrm{~h}$, then dried at $45^{\circ} \mathrm{C}$ for the extraction experiment.

Arabinose (Ara), galactose (Gal), glucose (Glc), fructose (Fru), xylan (Xyl), rhamnose (Rha), mannose (Man), glucuronic acid (GlcA), galacturonic acid (GalA), trifluoroacetic acid (TFA), acarbose, porcine pancreatic $\alpha$-amylase, $\alpha$-glucosidase, p-nitrophenyl- $\alpha$-Dglucopyranoside (pNPG), bovine serum albumin (BSA), 1,1-diphenyl-2-picric acid (DPPH), 2,2' - diazo-bis-3-ethylbenzothiazoline-6-sulfonic acid (ABTS), Folin ciocalteu reagent were purchased from Shanghai Huicheng Biotechnology Co., Ltd. (Shanghai, China); $\mathrm{Na}_{2} \mathrm{CO}_{3}$, $\left(\mathrm{NH}_{4}\right)_{2} \mathrm{SO}_{4}, \mathrm{~K}_{2} \mathrm{HPO}_{4}, \mathrm{Na}_{2} \mathrm{HPO}_{4}, \mathrm{NaH}_{2} \mathrm{PO}_{4}, \mathrm{HCl}$, ethanol, and Congo red were analytical grade, and purchased from Merck Chemical Technology (Shanghai) Co., Ltd. (Shanghai, China). Methanol (Thermo Fisher Scientific, Waltham, MA, USA) was HPLC grade in HPLC experiment.

\subsection{Preparation of ATPS}

As the turbidity titration method previously described [41], the ATPS of ethanol/salt system and the phase diagrams of ATPS were carried out as follows: salt $\left(\mathrm{Na}_{2} \mathrm{CO}_{3}\right.$, $\left.\left(\mathrm{NH}_{4}\right)_{2} \mathrm{SO}_{4}, \mathrm{~K}_{2} \mathrm{HPO}_{4}, \mathrm{Na}_{2} \mathrm{HPO}_{4}, \mathrm{NaH}_{2} \mathrm{PO}_{4}\right)$, water and ethanol were mixed well and cultivated at $50{ }^{\circ} \mathrm{C}$. With the addition of salt and water, the weight and volume ratios of 
salt and ethanol were recorded at the phase transformation point that the system showed two phase separation, respectively. Finally, the phase diagrams of ATPS were plotted on the basis of the recorded data.

\subsection{Extraction of $M H P$}

The samples were added into the prepared ATPS (Table S1) at the material-liquid ratio of $1: 20 \mathrm{~g} / \mathrm{mL}$, then sonicated in an ultrasonic bath (UP-250, Shanghai Bilang Instrument Manufacturing Co., Ltd. China) at an ultrasound power of $50 \mathrm{~W}$ for $20 \mathrm{~min}$. The extraction temperature was set to $50{ }^{\circ} \mathrm{C}$. The upper and lower phases were collected and filtrated, respectively. The solution was dialyzed in distilled water for 3 days (3500 Da, Beijing Ruida Henghui Technology Development Co., Ltd., Beijing, China), then a vacuum freeze drier was used to obtain MHP. Lastly, the extraction efficiency $(E)$, the extraction yield $\left(Y_{L}\right)$ and the purity $\left(P_{L}\right)$ of MHP were analyzed by phenol sulfuric acid method with glucose standard, and shown in Equations (2)-(4):

$$
\begin{gathered}
Y_{L}(\%)=\frac{C_{L} V_{L}}{M_{1}} \times 100 \\
P_{L}(\%)=\frac{C_{L} V_{L}}{M_{2}} \times 100 \\
E(\%)=\frac{C_{L} V_{L}}{C_{L} V_{L}+C_{U} V_{U}} \times 100
\end{gathered}
$$

where $V_{L}, C_{L}$ are the volume of lower phase $(\mathrm{mL})$ and the concentration of $\mathrm{MHP}(\mu \mathrm{g} / \mathrm{mL})$, respectively. $V_{U}, C_{U}$ are the volume of upper phase $(\mathrm{mL})$ and the concentration of MHP ( $\mu \mathrm{g} / \mathrm{mL})$, respectively. $M_{1}, M_{2}$ are the quality of the $M$. hupehensis powder and the dry matter of lower phase (mg).

\subsection{Optimization of Extraction Condition}

A suitable range of experimental factors, including material-liquid ratio $\left(X_{1}, 10-30 \mathrm{~mL} / \mathrm{g}\right)$, ultrasonic power $\left(X_{2}, 40-80 \mathrm{~W}\right)$, ultrasonic time $\left(X_{3}, 10-50 \mathrm{~min}\right)$, were selected to the improvement of the extraction efficiency, and carried out by a single-factor design. In accordance with the single-factor experimental results, a three-level-three-variable Box-Behnken design (BBD) was conducted to optimize the best combination of extraction variables $\left(X_{1}, X_{2}, X_{3}\right)$ at three levels (Tables S2 and S3). The extraction efficiency of MHP (E) was used as the response value. The relationship between the independent and dependent variables is shown in Equation (5):

$$
E=\beta_{0}+\sum_{j=1}^{k} \beta_{j} X_{j}+\sum_{j=1}^{k} \beta_{j j} X_{j}^{2}+\sum_{i} \sum_{<j=2}^{k} \beta_{i j} X_{i} X_{j}+e_{i}
$$

where $E$ is the extraction efficiency of MHP (\%); $X_{i}$ and $X_{j}$ are the coded variables ( $i$ and $j$ range from 1 to $k) ; \beta_{0}, \beta_{j}, \beta_{j j}$, and $\beta_{i j}$ are regression coefficients of intercept coefficient, linear, quadratic, and the second-order terms, respectively; $k$ is the number of independent parameters $(k=4)$ and $e_{i}$ is the error. The applicability of the predicted polynomial model and the optimized extraction conditions was evaluated by the coefficients of determination $\left(R^{2}\right)$, F-test $(p=0.05)$, and an additional experiment, respectively.

\subsection{Characterization of $M H P$}

3.5.1. Flourier Transformation Infrared Spectroscopy (FT-IR) Analysis

According to the ratio of $1: 100, \mathrm{MHP}(2.0 \mathrm{mg})$ was mixed with $\mathrm{KBr}$, and the mixture was grinded and pressed together. The wavelength of FTIR Spectrometer (Shanghai Cupboard technology development Co., Ltd., Shanghai, China) was set at $4000-400 \mathrm{~cm}^{-1}$. 


\subsubsection{Congo Red Test}

MHP solution $(1.0 \mathrm{~mL}, 2.0 \mathrm{mg} / \mathrm{mL})$ and Congo red reagent $(1.0 \mathrm{~mL}, 80.0 \mu \mathrm{mol} / \mathrm{L})$ were mixed thoroughly. Then $\mathrm{NaOH}$ solution $(1.0 \mathrm{~mol} / \mathrm{L})$ was gradually added to obtain different concentrations of $\mathrm{NaOH}$ solution $(0,0.1,0.15,0.2,0.25,0.3,0.35,0.4,0.45,0.5 \mathrm{~mol} / \mathrm{L})$. Water was set as the control group. Finally, the maximum absorbance of $\mathrm{NaOH}$ solution was measured by UV spectrometer (Beijing Planck New Technology Co., Ltd., Beijing, China), and the curves of concentration-maximum absorption wavelength were obtained.

\subsubsection{Circular Dichroism (CD) Spectroscopy Analysis}

The asymmetric structure and structure change of WHP was determined by CD spectrum. WHP solution $(3 \mathrm{mg} / \mathrm{mL})$ was used in this study. The spectra were recorded in the far UV range (200-250 nm) with a $1 \mathrm{~mm}$ quartz cell on a J-810 CD spectrophotometer (JASCO Co., Tokyo, Japan). The setting conditions of CD spectra are as follows: the scanning rate of $60 \mathrm{~nm} / \mathrm{min}$, spectral resolution of $1 \mathrm{~nm}$, response of $1 \mathrm{~s}$, and bandwidth of $1 \mathrm{~nm}$.

\subsubsection{Monosaccharide Composition Analysis}

The monosaccharide composition and mole ratio of MHP were quantitatively analyzed by HPLC combined with precolumn derivatization method. MHP $(5 \mathrm{mg})$ were dispersed in TFA $(2 \mathrm{~mL}, 4 \mathrm{M})$ sealed tube, and hydrolyzed to monosaccharides at $110^{\circ} \mathrm{C}$. Then, the sample solution was derived by using PMP-HPLC analysis. Finally, the derivatization product of MHP was filtered, and stored for the following HPLC analysis.

The HPLC equipment was an ultimate 3000 system (Thermo Scientific, USA) in the isocratic elution mode. The experiment conditions were set as follows: COSMOSIL $5 \mathrm{C}_{18^{-}}$ PAQ $4.6 \times 250 \mathrm{~mm}$ was eluted with acetonitrile and phosphate buffer as mobile phase at a flow rate of $1.0 \mathrm{~mL} / \mathrm{min}$ at $35^{\circ} \mathrm{C}$.

\subsection{Assay for Antioxidant Activity of MHP}

The DPPH, ABTS and superoxide radical scavenging activities were evaluated according to the method previously described with some modifications [32]. Ascorbic acid was used as a positive control. The radical scavenging was calculated according to the following Equation (6):

$$
\text { Scavenging activity }(\%)=\left(1-\frac{A_{i}-A_{j}}{A o}\right) \times 100
$$

where $A_{i}, A_{0}, A_{j}$ was the absorbance of sample, blank control (without sample), the blank reagent, respectively. Sample concentration providing $50 \%$ inhibition $\left(\mathrm{IC}_{50}\right)$ was calculated according to the graph plotting inhibition percentage.

\subsection{In Vitro Antihyperglycemic Activity}

\subsection{1. $\alpha$-Glucosidase Inhibitory Activity}

The antihyperglycemic activity of MHP in vitro was evaluated by $\alpha$-glucosidase inhibition ability according to the method, that was slightly modified [38]. In short, $50 \mu \mathrm{L}$ $\alpha$-glucosidase $(0.5 \mathrm{U} / \mathrm{mL}$, dissolved in $0.2 \mathrm{M} \mathrm{PBS}, \mathrm{pH}$ 6.9) was mixed with $50 \mu \mathrm{L}$ MHP sample solution of different concentrations $(0.2-3.0 \mathrm{mg} / \mathrm{mL})$, and then incubated at $37^{\circ} \mathrm{C}$ for $10 \mathrm{~min}$. Then, $50 \mu \mathrm{L}$ pNPG $(5 \mathrm{mM})$ was added and incubated at $37^{\circ} \mathrm{C}$ for $20 \mathrm{~min}$. After that, $80 \mu \mathrm{L}$ of $\mathrm{Na}_{2} \mathrm{CO}_{3}$ solution $(0.2 \mathrm{M})$ was added to stop the reaction and the absorbance was detected at $405 \mathrm{~nm}$. Acarbos was used as the positive control and blank control without enzyme. The $\alpha$-glucosidase inhibitory activity was calculated according to the following Equation (7):

$$
\text { Inhibition rate }(\%)=\left(1-\frac{A_{s}-A_{b}}{A_{o}}\right) \times 100
$$


Among them, $A_{s}, A_{b}$, and $A_{0}$ are the absorbance of the test sample system, the mixture of pNPG and MHP without enzyme, and the mixture of PNPG and enzyme without MHP, respectively.

Fluorescence measurements were preformed via a DSF-150WT fluorescence spectrometer (Disofoo measurement technology Co., Ltd., Jiangsu, China). The final concentration of $\alpha$-glucosidase was prepared to be $1 \mathrm{U} / \mathrm{mL}$ in all solutions, while the different MHP final concentrations in the solutions were $0,0.2,0.4,0.6,0.8,1 \mathrm{mg} / \mathrm{mL}$, respectively. $\alpha$ glucosidase and MHP were mixed well. The excitation wavelength and excitation slit were 280 and $5 \mathrm{~nm}$, respectively. The fluorescence spectra of each mixture was obtained in the range of $300-450 \mathrm{~nm}[19,20]$.

\subsubsection{Inhibition of MHP on Advanced Glycation end Products (AGEs) Formation}

To study the capability of antiglycation of MHP, BSA/Glc and aminoguanidine were used as the reaction model and positive control, respectively [42]. A series of MHP (50, 200 and $400 \mu \mathrm{g} / \mathrm{mL}$ ) were added into the mixed PBS solution (0.1 M, pH 7.4) of BSA $(240 \mu \mathrm{L}, 20 \mathrm{mg} / \mathrm{mL})$ and Glc $(120 \mu \mathrm{L}, 20 \mathrm{mmol} / \mathrm{L})$, then incubated together in a capped test tube $(10 \mathrm{~mL})$ at $80^{\circ} \mathrm{C}$. After $24 \mathrm{~h}$, the content of fluorescent AGEs was determined by a DSF-150WT fluorescence spectrometer at the excitation wavelength $360 \mathrm{~nm}$, the emission wavelength $453 \mathrm{~nm}$. The inhibition of MHP on AGEs was calculated according to the following Equation (8):

$$
\text { Inhibition } \operatorname{rate}(\%)=\frac{F-F_{0}}{F_{0}} \times 100
$$

where $F, F_{0}$ was the fluorescence intensity of sample, blank control (without sample), respectively.

\section{Conclusions}

Malus hupehensis (M. hupehensis), an edible and medicinal plant with significant antioxidant and hypoglycemic activity, has been applied to new resource foods. However, the structural characterization and biological effects of its polysaccharides (MHP) are less known. The optimum extraction parameters to achieve the highest extraction efficiency $(47.63 \%)$, the yield $(1.68 \%)$ and purity of MHP $(89.6 \%)$ by ultrasonic-assisted aqueous two-phase extraction (ATPS) were obtained under the liquid-to-solid ratio of $23 \mathrm{~g} / \mathrm{mL}$, ultrasonic power of $65 \mathrm{~W}$, and ultrasonic time of $33 \mathrm{~min}$. The physicochemical properties and biological activity of MHP were investigated. According to the analysis results, MHP was composed of nine monosaccharides including Man, GlcA, Rha, GalA, Glc, Gal, Xyl, Ara, and Fuc, in which Ara and Gal were the main components, and the content of GlcA was the lowest. In in vitro activity analysis, MHP showed a significant antioxidant capacity, and an inhibition activity of $\alpha$-glucosidase and the AGEs formation in the BSA/Glc reaction model. The biological properties of polysaccharides might be attributed to the physicochemical characteristic of MHP. According to fluorescence analyses, MHP interacted with $\alpha$-glucosidase and changed the internal microenvironment of the enzyme, and inhibited the AGEs formation, which provided more evidence for the antihyperglycemic mechanism of MHP. The results suggest that ATPS is an efficient and environmentally friendly solvent system, and M. hupehensis has broad application prospects in functional foods, healthcare products, and pharmaceuticals.

Supplementary Materials: The following are available online, Table S1: Experimental design and results of response surface methodology: Ethanol/salt ratio of ATPS, Table S2: Experimental design independent variables and their levels, Table S3: Experimental design and results of response surface methodology.

Author Contributions: P.L. and H.X.: Investigation (equal); Formal analysis (equal). M.X.: Data curation (supporting). Y.S., H.Y. and J.T.: Funding acquisition (equal), Project administration (equal); 
supervision (equal). X.C.: Writing-original draft; Validation; Writing—review and editing. All authors have read and agreed to the published version of the manuscript.

Funding: This research was funded by Health and Family Planning Commission of Wuhan Municipality, grant number WZ20Q10 and The APC was funded by Yanqi Su.

Data Availability Statement: Research data are not shared.

Acknowledgments: This work was supported by Tsinghua University and Jilin Agricultural University.

Conflicts of Interest: The authors have declared no conflict of interest.

Sample Availability: Samples of Malus hupehensis and polysaccharides are available from the authors.

\section{References}

1. Liu, Q.; Zeng, H.; Jiang, S.; Zhang, L.; Yang, F.; Chen, X.; Yang, H. Separation of polyphenols from leaves of Malus hupehensis (Pamp.) Rehder by off-line two-dimensional high speed counter-current chromatography combined with recycling elution mode. Food Chem. 2015, 186, 139-145. [CrossRef]

2. Hu, Q.W.; Chen, Y.Y.; Jiao, Q.Y.; Khan, A.; Shan, J.; Cao, G.D.; Li, F.; Zhang, C.; Lou, H.X. Polyphenolic compounds from Malus hupehensis and their free radical scavenging effects. Nat. Prod. Res. 2017, 32, 2152-2158. [CrossRef]

3. Liu, J.; Guo, D.Y.; Fan, Y.; Sun, J.; Cheng, J.X.; Shi, Y.J. Experimental study on the antioxidant activity of Malus hupehensis (Pamp.) Rehd extracts in vitro and in vivo. J. Cell Biochem. 2019, 120, 11878-11889. [CrossRef] [PubMed]

4. Wang, S.Q.; Zhu, X.F.; Wang, X.N.; Shen, T.; Xiang, F.; Lou, H.X. Flavonoids from Malus hupehensis and their cardioprotective effects against doxorubicin-induced toxicity in H9c2 cells. Phytochemistry 2013, 87, 119-125. [CrossRef] [PubMed]

5. Guo, D.Y.; Dang, J.L.; Yang, H.; Fan, Y.; Cheng, J.X.; Shi, Y.J.; Zhang, X.F.; Zou, J.B. Simultaneous determination of four flavonoids in rat plasma after oral administration of Malus hupehensis (Pamp.) Rehd. extracts by UPLC-MS/MS and its application to a pharmacokinetics study. J. Pharm. Biomed. Anal. 2020, 177, 112869-112876. [CrossRef] [PubMed]

6. Wen, C.; Wang, D.S.; Li, X.; Huang, T.; Huang, C.; Hu, K.F. Targeted isolation and identification of bioactive compounds lowering cholesterol in the crude extracts of crabapples using UPLC-DAD-MS-SPE/NMR based on pharmacology-guided PLS-DA. J. Pharm. Biomed. Anal. 2018, 150, 144-151. [CrossRef] [PubMed]

7. Liu, M.Z.; Huang, X.Q.; Liu, Q.; Chen, M.; Liao, S.; Zhu, F.W.; Shi, S.Y.; Yang, H.; Chen, X.Q. Rapid screening and identification of antioxidants in the leaves of Malus hupehensis using off-line two-dimensional HPLC-UV-MS/MS coupled with a 1,1-diphenyl-2picrylhydrazyl assay. J. Sep. Sci. 2018, 41, 2536-2543. [CrossRef]

8. Lv, Q.Y.; Lin, Y.S.; Tan, Z.X.; Jiang, B.P.; Xu, L.J.; Ren, H.Q.; William, C.T.; Chan, C.; Lee, C.; Gu, Z.B.; et al. Dihydrochalconederived polyphenols from tea crab apple (Malus hupehensis) and their inhibitory effects on $\alpha$-glucosidase in vitro. Food Funct. 2019, 10, 2881-2887. [CrossRef] [PubMed]

9. Cai, X.; Xiao, M.; Zou, X.W.; Tang, J.T.; Huang, B.S.; Xue, H.K. Extraction and separation of flavonoids from Malus hupehensis using high-speed countercurrent chromatography based on deep eutectic solvent. J. Chromatogr. A. 2021, 1641, 461998-462006. [CrossRef]

10. Fu, Y.; Shi, L.; Ding, K. Structure elucidation and anti-tumor activity in vivo of a polysaccharide from spores of Ganoderma lucidum (Fr.) Karst. Int. J. Biol. Macromol. 2019, 141, 693-699. [CrossRef]

11. Wu, S.; Li, F.; Jia, S.; Ren, H.; Gong, G.; Wang, Y.; Lv, Z. Drying effects on the antioxidant properties of polysaccharides obtained from Agaricus blazei Murrill. Carbohyd. Polym. 2014, 103, 414-417. [CrossRef]

12. Kou, L.; Du, M.Z.; Liu, P.J.; Zhang, B.H.; Zhang, Y.Z.; Yang, P.; Shang, M.Y.; Wang, X.D. Anti-diabetic and anti-nephritic activities of Grifola frondosa Mycelium polysaccharides in diet-streptozotocin-induced diabetic rats via modulation on oxidative stress. Appl. Biochem. Biotech. 2019, 187, 310-322. [CrossRef]

13. Jia, Y.N.; Gao, X.D.; Xue, Z.H.; Wang, Y.J.; Lu, Y.P.; Zhang, M.; Panichayupakaranant, P.; Chen, H.X. Characterization, antioxidant activities, and inhibition on $\alpha$-glucosidase activity of corn silk polysaccharides obtained by different extraction methods. Int. J. Biol. Macromol. 2020, 163, 1640-1648. [CrossRef] [PubMed]

14. Yang, X.; Yang, Y.H.; Chen, H.; Xu, T.; Li, C.H.; Zhou, R.G.; Gao, L.L.; Han, M.M.; He, X.T.; Chen, Y. Extraction, isolation, immunoregulatory activity, and characterization of Alpiniae oxyphyllae fructus polysaccharides. Int. J. Biol. Macromol. 2020, 155, 927-937. [CrossRef] [PubMed]

15. Teng, C.; Qin, P.; Shi, Z.; Zhang, W.; Yang, X.; Yao, Y.; Ren, G. Structural characterization and antioxidant activity of alkali-extracted polysaccharides from quinoa. Food Hydrocolloid. 2021, 113, 106392-106402. [CrossRef]

16. Zhou, X.; Wang, B.L.; Fu, L.; Yuan, M.; Liu, J.; Zhou, L.; Ding, C. Characterization and antioxidant activities of polysaccharides from the leaves of Lilium lancifolium Thunb. Int. J. Med. Sci. 2016, 92, 148-155.

17. Cheong, K.L.; Xia, L.X.; Liu, Y. Isolation and Characterization of polysaccharides from Oysters (Crassostrea gigas) with anti-tumor activities using an aqueous two-phase system. Mar. Drugs. 2017, 15, 338. [CrossRef]

18. Cheng, Z.Y.; Song, H.Y.; Cao, X.L.; Shen, Q.H.; Han, D.D.; Zhong, F.L.; Hu, H.B.; Yang, Y.J. Simultaneous extraction and purification of polysaccharides from Gentiana scabra Bunge by microwave-assisted ethanol-salt aqueous two-phase system. Ind. Crop. Prod. 2017, 102, 75-87. [CrossRef] 
19. Xing, J.M.; Li, F.F. Separation and purification of aloe polysaccharides by a combination of membrane ultrafiltration and aqueous two-phase extraction. Appl. Biochem. Biotech. 2009, 158, 11-19. [CrossRef]

20. Ji, X.L.; Peng, Q.; Yuan, Y.P.; Liu, F.; Wang, M. Extraction and physicochemical properties of polysaccharides from Ziziphus Jujuba cv. Muzao by ultrasound-assisted aqueous two-phase extraction. Int. J. Biol. Macromol. 2018, 108, 541-549. [CrossRef]

21. Zhu, L.; Lu, Y.; Sun, Z.; Han, J.; Tan, Z.J. The application of an aqueous two-phase system combined with ultrasonic cell disruption extraction and HPLC in the simultaneous separation and analysis of solanine and Solanum nigrum polysaccharide from Solanum nigrum unripe fruit. Food Chem. 2020, 304, 125383. [CrossRef]

22. Lin, Y.; Zeng, H.; Wang, K.; Lin, H.; Li, P.; Huang, Y.; Zhou, S.; Zhang, W.; Chen, C.; Fan, H. Microwave-assisted aqueous two-phase extraction of diverse polysaccharides from Lentinus edodes: Process optimization, structure characterization and antioxidant activity. Int. J. Biol. Macromol. 2019, 136, 305-315. [CrossRef]

23. Huang, Y.X.; Wu, X.H.; Zhou, S.Y.; Lin, Y.Y.; Zhang, W.; Fu, C.J.; Luo, L.C.; Wang, K.; Xie, X.J.; Fan, H.J. Biphasic extraction of different polysaccharides from Radix Sophorae Tonkinensis by microwave-assisted aqueous two-phase extraction: Process optimization, structural characterization and mechanism exploration. Sep. Purif. Technol. 2018, 207, 187-198. [CrossRef]

24. Yan, J.K.; Ma, H.L.; Pei, J.J.; Wang, Z.B.; Wu, J.Y. Facile and effective separation of polysaccharides and proteins from Cordyceps sinensis mycelia by ionic liquid aqueous two-phase system. Sep. Purif. Technol. 2014, 135, 278-284. [CrossRef]

25. Tang, W.; Lin, L.H.; Xie, J.H.; Wang, Z.J.; Wang, H.; Wan, Q.; Dong, Y.J.; Shen, M.Y.; Xie, M.Y. Effect of ultrasonic treatment on the physicochemical properties and antioxidant activities of polysaccharide from Cyclocarya paliurus. Carbohyd. Polym. 2016, 151, 305-312. [CrossRef]

26. Zhang, X.F.; Teng, G.X.; Zhang, J. Ethanol/salt aqueous two-phase system based ultrasonically assisted extraction of polysaccharides from Lilium davidiivar. unicolor Salisb: Physicochemical characterization and antiglycation properties. J. Mol. Liq. 2018, 256, 497-506. [CrossRef]

27. Chen, Z.; Zhang, W.; Tang, X.Y.; Fan, H.J.; Xie, X.J.; Wan, Q.; Wu, X.H.; Tang, J.Z. Extraction and characterization of polysaccharides from Semen Cassiae by microwave-assisted aqueous two-phase extraction coupled with spectroscopy and HPLC. Carbohyd. Polym. 2016, 144, 263-270. [CrossRef]

28. Su, Y.; Li, L. Structural characterization and antioxidant activity of polysaccharide from four auriculariales. Carbohyd. Polym. 2020, 229, 115407-115416. [CrossRef]

29. Chikari, F.; Han, J.; Wang, Y.; Ao, W. Synergized subcritical-ultrasound-assisted aqueous two-phase extraction, purification, and characterization of Lentinus edodes polysaccharides. Process Biochem. 2020, 95, 297-306. [CrossRef]

30. Pol, K.; Graaf, K.D.; Bruin, D.D.; Balvers, M.; Mars, M. The effect of replacing sucrose with L-arabinose in drinks and cereal foods on blood glucose and plasma insulin responses in healthy adults. J. Funct. Foods. 2020, 73, 104114. [CrossRef]

31. Preuss, H.G.; Echard, B.; Bagchi, D.; Stohs, S. Inhibition by natural dietary substances of gastrointestinal absorption of starch and sucrose in rats and pigs: 1. Acute Studies. Int. J. Med. Sci. 2007, 4, 196-202. [CrossRef] [PubMed]

32. Xie, J.H.; Dong, C.J.; Nie, S.P.; Li, F.; Wang, Z.J.; Shen, M.Y.; Xie, M.Y. Extraction, chemical composition and antioxidant activity of flavonoids from Cyclocarya paliurus (Batal.) Iljinskaja leaves. Food Chem. 2015, 186, 97-105. [CrossRef] [PubMed]

33. Shang, X.L.; Liu, C.Y.; Dong, H.Y.; Peng, H.H.; Zhu, Z.Y. Extraction, purification, structural characterization, and antioxidant activity of polysaccharides from wheat bran. J. Mol. Struct. 2021, 1233, 130096-130106. [CrossRef]

34. Wang, L.B.; Li, L.Y.; Gao, J.Y.; Huang, J.; Yang, Y.; Xu, Y.Q.; Liu, S.; Yu, W.Q. Characterization, antioxidant and immunomodulatory effects of selenized polysaccharides from dandelion roots. Carbohyd. Polym. 2021, 260, 117796-117806. [CrossRef]

35. Wu, Y.T.; Huo, Y.F.; Xu, L.; Xu, Y.Y.; Wang, X.L.; Zhou, T. Purification, characterization and antioxidant activity of polysaccharides from Porphyra haitanensis. Int. J. Biol. Macromol. 2020, 165, 2116-2125. [CrossRef]

36. Ni, M.T.; Hu, X.; Gong, D.M.; Zhang, G.W. Inhibitory mechanism of vitexin on $\alpha$-glucosidase and its synergy with acarbose. Food Hydrocoll. 2020, 105, 105824-105835. [CrossRef]

37. Lv, Q.Q.; Cao, J.J.; Liu, R.; Chen, H.Q. Structural characterization, $\alpha$-amylase and $\alpha$-glucosidase inhibitory activities of polysaccharides from wheat bran. Food Chem. 2021, 341, 128218-128229. [CrossRef]

38. Xue, H.K.; Zhu, X.H.; Tan, J.Q.; Fan, L.L.; Li, Q.; Tang, J.T.; Cai, X. Counter-current fractionation-assisted bioassay-guided separation of active compound from blueberry and the interaction between the active compound and $\alpha$-glucosidase. Foods 2021, 10, 509. [CrossRef]

39. Wang, X.; Zhang, L.S.; Dong, L.L. Inhibitory effect of polysaccharides from pumpkin on advanced glycation end-products formation and aldose reductase activity. Food Chem. 2012, 130, 821-825. [CrossRef]

40. Yang, Y.; Li, Y.; Yin, D.; Chen, S.; Gao, X. Coptis chinensis polysaccharides inhibit advanced glycation end product formation. J. Med. Food. 2016, 19, 593-600. [CrossRef]

41. Du, L.P.; Cheong, K.L.; Liu, Y. Optimization of an aqueous two-phase extraction method for the selective separation of sulfated polysaccharides from a crude natural mixture. Sep. Purif. Technol. 2018, 202, 290-298. [CrossRef]

42. Lan, M.Y.; Li, H.M.; Tao, G.; Lin, J.; Lu, M.W.; Yan, R.A.; Huang, J.Q. Effects of four bamboo derived flavonoids on advanced glycation end products formation in vitro. J. Funct. Foods. 2020, 71, 103976-103984. [CrossRef] 